\title{
A constituição de um imaginário de língua homogênea na/pela gramática
}

Maria Iraci Sousa Costa ${ }^{1}$

\begin{abstract}
This work aims to propose a reflection about the discursive mechanisms that contribute for the constitution of an imaginary of language homogeneity in grammar, considering the way how the grammarian defines and designates language. In order to do this, we refer to the Modern Portuguese Grammar (1977 [1961]), by Evanildo Bechara, a reputed brazilian grammarian, to investigate how is the relation between the subject with language and history in the consitution of homogeneity imaginary, taking into account the effects of sense of what is said and also not said in the grammarian discourse.
\end{abstract}

Key-words: language, unity, homogeneity

Resumo: O presente artigo tem o objetivo de propor uma reflexão sobre os mecanismos discursivos que contribuem para a constituição de um imaginário de homogeneidade da língua na gramática, considerando a forma como o gramático define e designa a língua. Para tanto, reportamo-nos à Moderna Gramática Portuguesa (1977 [1961]), de Evanildo Bechara, renomado gramático brasileiro, para investigar como se dá a relação do sujeito com a língua e com a história na constituição do imaginário de homogeneidade, considerando os efeitos de sentido do que é dito e também do não dito no discurso do gramático.

Palavras-chave: língua, unidade, homogeneidade.

Algumas considerações sobre as determinações históricas do sujeito brasileiro em relação à língua

Propor uma reflexão sobre o imaginário de unidade da língua na gramática brasileira é também questionar acerca da constituição da história da língua num país que foi colonizado pelo europeu e sobre a importância da gramática na dominação de uma cultura sobre a outra. É, também, questionar sobre como o sujeito se significa ao designar a língua que fala, discurso esse que é atravessado pelo discurso do colonizador sobre o Brasil e sobre o brasileiro. Essa é a tarefa a que nos lançamos no presente artigo.

$\mathrm{Na}$ história da língua no Brasil, ressoa fortemente um discurso produzido pelo colonizador sobre o brasileiro, considerando que "o brasileiro, para significar, tem como memória (domínio do saber) o já-dito europeu. Essa é a 'heterogeneidade’ que o pega

1 Doutoranda do Programa de Pós-Graduação em Letras - Estudos Linguísticos da Universidade Federal de Santa Maria -UFSM 


\section{Conexão Letras}

desde a origem. A sua fala é falada pela memória do outro (europeu)" (ORLANDI, 1990: 51). A forma como é contada a história da constituição do Brasil e sua relação com a(s) língua(s) passa pelo olhar do colonizador. Esse olhar tende a apagar da história aquilo que é anterior à chegada do europeu, instaurando um corte para constituir uma história que tem início no século XVI, quando os portugueses tomam posse daquilo que pertencia aos índios e os submetem a uma condição de colonizado.

No que tange à língua no Brasil colônia, não poderia ser diferente, uma vez que os colonizadores, pressupondo a sua superioridade linguística, avaliam a língua do índio a partir da sua língua. Nesse sentido, segundo Mariani (2003), "a colonização linguística engendrada pela metrópole portuguesa é construída em torno da ideologia do déficit” ( $p$. 75), o que é apreendido a partir da falta do F, do $\mathrm{R}$ e do L na língua geral ${ }^{2}$. Tal lacuna significava, para o colonizador, a falta de fé (F), a falta de um rei (R), a falta de uma lei (L) e, consequentemente, a ausência de um poder religioso, de um poder real central e, também, de uma administração jurídica. Segundo Mariani (Ibid.), "na ótica do colonizador português, essas três instituições nucleares do aparelho de Estado - religião, realeza e direito - simbolizam um estágio avançado de civilização que têm como base uma única língua nacional gramatizada e escrita" (p. 75).

Esse imaginário de superioridade da língua e o sentido dado à falta do $\mathrm{F}$, do $\mathrm{R}$ e do $\mathrm{L}$ servem para legitimar a dominação do colonizador sobre a língua do colonizado. Entretanto, era preciso reconhecer que o caminho mais rápido para a expansão da evangelização era através da adoção do vernáculo local. Desse modo, para realizar a conversão religiosa cristã dos índios e a sua submissão ao império, os jesuítas desenvolveram um trabalho de gramatização da língua geral (tupi), o que permitiu que fossem realizadas traduções, adaptações de textos de doutrina religiosa em língua geral. Esse processo de gramatização pelos jesuítas teve como efeito a expansão da língua geral em toda a colônia, o que não favorecia os interesses de colonização da Coroa portuguesa. Dessa forma, só mais tardiamente, no século XVIII, é que a língua portuguesa foi imposta na colônia durante o reinado de Dom José I, sob o comando do Marquês de Pombal, por meio do ato políticojurídico "Diretório dos índios", o qual determinava que a língua a ser falada, escrita e ensinada na colônia era a língua portuguesa (MARIANI, 2003). Esse acontecimento ressoará no discurso do brasileiro, fazendo retornar uma memória (re)significando-a, a de que só há uma língua no Brasil, a língua portuguesa, a língua do colonizador.

Quando o Brasil conquista sua independência política e deixa de ser colônia de Portugal, no século XIX, as discussões em torno da língua e do nome da língua no Brasil passam a ser um assunto também dos brasileiros. Segundo Guimarães (2000), "a questão da nomeação da língua da nação brasileira já se põe no plano da lei logo após a Independência" (p. 170). De acordo com o autor, em 1827, foi aprovada uma lei que determinava que o ensino de língua na escola deveria estar pautado na gramática da “Língua Nacional”. Segundo Dias (1996), “a expressão 'língua nacional' aparece pela primeira vez em um texto legal, e seria utilizada nos textos das Constituições Brasileiras até meados do século atual" (p. 12).

2 Língua geral designava, nos séculos XVI e XVII, o tupi, "a língua indígena majoritariamente falada na costa do Brasil, e que nas primeiras décadas da colonização era chamado de língua brasílica" (MARIANI, 2003, p. 76 [grifos da autora]). Essas considerações sobre a falta do F, L e R aparecem na descrição linguística, proposta pelo Padre José de Anchieta, na obra "Artes de Gramática da língua mais falada na Costa do Brasil” (1595). Inclusive, uma das primeiras considerações nessa gramática é o apontamento da falta das letras f, $1, \mathrm{~s}, \mathrm{z}, \mathrm{rr}$ : “esta lingoa do Brasil não ha f, 1, s, z, rr. dobrado nem muta com liquida, vt cra, pra, \&c." (ANCHIETA, 1990 [1595], p. 23) 
Essa lei, a que designava a língua no Brasil como "Língua Nacional”, foi aprovada após ser instaurada a discussão em torno do nome dessa língua, depois de o Deputado José Clemente propor que o diploma dos médicos cirurgiões fosse emitido em "linguagem brasileira". Apesar da intervenção da lei em designar a língua no/do Brasil como "língua nacional”, Guimarães (Ibid.) insiste: "qual é o idioma nacional a que é necessário dar um nome?" (p. 170-171), uma vez que a designação "língua nacional" não só coloca em suspenso a não nomeação da língua em relação ao colonizador, mas também não assume a identidade da língua com o brasileiro.

A discussão sobre o nome do idioma nacional retorna no século $\mathrm{XX}$, nas décadas de 30 e 40, no Parlamento brasileiro, produzindo diferentes posicionamentos em relação às designações "língua portuguesa" e "língua brasileira" para definir a "língua nacional". Pela Constituição de 1946, ficou definido que o nome do idioma nacional do Brasil é língua portuguesa, "e é nessa medida que a Constituição de 46 mantém na memória brasileira o sentido de que no Brasil se fala uma só língua. Ou seja, enquanto povo civilizado, o povo brasileiro só fala uma língua" (GUIMARÃES, 2000: 176). Entretanto, a construção de uma língua (imaginária) nacional sugere outros questionamentos, como, por exemplo, "que língua nós apagamos para ter uma língua nacional (o português)? De que língua (ou línguas) foi necessário nos distanciarmos para termos uma língua portuguesa?” (ORLANDI, 1990: 74).

Nessa medida, ressoa no discurso do brasileiro a forma como, historicamente, ele foi significado pelo colonizador, fazendo retornar um já-dito que se tornou naturalizado, que nega a existência de outras línguas no Brasil. Trata-se de um assujeitamento ao Estado, sustentado sobre um imaginário de unidade, o qual remete a um efeito de homogeneidade da língua que, por sua vez, é o efeito da história da colonização (ORLANDI, 2002). Tendo em vista essa insistência do Estado em sustentar um imaginário de homogeneidade e de unidade da língua, entendemos que "a língua nacional torna-se homogênea, para os fins políticos a que serve, sendo refratadas as condições concretas sob as quais ela funciona" (ZANDWAIS, 2012: 180). A discursivização sobre a homogeneidade e unidade da língua trabalha para que as outras línguas sejam silenciadas e para que a língua do colonizador seja naturalizada como patrimônio da nação.

Tendo em vista esse jogo de forças que tende a apagar a historicidade da língua, tornando-a fixa e homogênea, Orlandi (1990) distingue duas concepções de língua: língua imaginária e língua fluida. Segundo a autora, "a língua imaginária é aquela que os analistas fixam com suas sistematizações e a língua fluida é aquela que não se deixa imobilizar nas redes dos sistemas e das fórmulas" (Ibid.:75 [grifos da autora]). A gramática, por exemplo, repousa sobre uma concepção de língua imaginária, na medida em que impõe um sistema de normas e coerções que regulamentam a língua como se esta fosse a-histórica e homogênea.

Considerando a história da constituição da(s) língua(s) no Brasil, mesmo após a sua emancipação política, ressoa historicamente um imaginário de que no Brasil só se fala uma língua e que essa língua é homogênea, imaginário esse instaurado no/pelo discurso do colonizador e que é naturalizado no discurso do brasileiro. Entretanto, "o efeito ideológico - colonialista - não nasce do nada. Sua materialidade específica é o discurso" (ORLANDI, 1990: 47). Desse modo, a nossa proposta é investigar como se constitui o imaginário de unidade da língua em uma gramática, produzida por um brasileiro, a partir da forma como o sujeito a define e a designa. Selecionamos a gramática como ponto de partida para a discussão do imaginário de unidade da língua por tratar-se de um instrumento de dominação de uma cultura sobre a outra (AUROUX, 1992) e, também, de imposição de uma língua homogênea, o que visa a silenciar as diferenças, negando-lhes à existência. Essa distribuição desigual da língua entre os falantes é, ainda, sustentada sobre a dicotomia certo e errado, o 


\section{Conexão Letras}

que impõe um padrão, seja para aprofundar as diferenças entre as classes hegemônicas e as demais classes, como forma de submetê-las, seja para excluir socialmente aqueles que não dominam a língua (imaginária) imposta pela gramática, naturalizando, desse modo, a desigualdade entre os sujeitos.

A partir de tais pressupostos, nosso objetivo é investigar como o gramático sustenta uma concepção de língua homogênea a partir da forma como ele a define e a designa, considerando o modo como o discurso impositivo do colonizador ressoa no discurso do gramático. Entendemos que as formas como a língua é designada também podem conduzir a um estudo sobre a “'desbabelização da língua e do sujeito', ou seja, como essa procura pela língua $\mathrm{x}, \mathrm{y}, \mathrm{z}$ traz a ideia de controle, de limite, de zona fronteiriça para se falar da língua e do sujeito" (SCHERER, 2012: 162). No caso do presente estudo, interessa-nos compreender a construção de um imaginário de "babelização da língua e do sujeito" a partir da forma como o gramático define e designa a língua, ou seja, como as diferentes formas de designar a língua convergem para um imaginário de controle do gramático sobre a homogeneidade da língua, simulando um efeito de que a língua portuguesa é uma só e que no Brasil só se fala uma língua, imaginário esse que remete ao mito bíblico de Babel, no tempo em que toda a terra só falava uma única língua.

\section{A determinação do sujeito na gramática}

A gramática constitui-se historicamente como um lugar de coerções do sujeito que determinam as formas de assujeitamento. Haroche (1992) traça um percurso da determinação do sujeito pela ordem religiosa até a jurídica, mostrando, através de mecanismos linguísticos, como a ambiguidade, a elipse e a incisa podem contribuir para o processo de individualização do sujeito na gramática. A hegemonia do Estado de direito sobre a ordem religiosa também tem consequências sobre as formas de assujeitamento, produzindo outras ilusões que regulam a forma como o sujeito vê o mundo e como ele o interpreta.

Na gramática, o sujeito está investido de uma ilusão necessária de que o seu dizer é completo e que a língua lhe permite dizer tudo. No caso da posição sujeito gramático, acredita-se ainda que, desse lugar, a língua é capaz de permitir dizer tudo sobre ela mesma. Não se trata apenas de uma ilusão de controle sobre o que é dito, mas também de construir um imaginário de língua homogênea e ideal, compatível com as classes hegemônicas, que acentue as diferenças em relação às demais classes, contribuindo, desse modo, para a marginalização daqueles que não dominam essa língua ideal, sustentada na gramática.

Esse imaginário de completude e totalidade repousa sobre os próprios enunciados que constituem a gramática e atribuem-lhe uma imagem de lugar da certeza e do interdito da dúvida. Dentre os enunciados que constituem a gramática, poderíamos citar a definição, formulação singular que assegura um efeito de completude e de evidência, que, por sua vez, produz um efeito de que o sujeito está fora da língua e que sua definição é indiferente à história e à interpretação. Nesse sentido, trata-se de uma formulação que permite a simulação de que o sujeito tem o controle sobre suas palavras, constituindo, desse modo, um espaço discursivo semanticamente estabilizado. Consideramos ainda que é pela definição que a gramática expõe a sua força impositiva, pois, o gramático, ao definir, interdita a interpretação, na medida em que determina o que dever ser entendido (que o sentido é esse e não outro, não há o que ser questionado, a ambiguidade e o equívoco estão em outro lugar, para além dos limites da gramática). Da mesma forma, o sujeito que define nega que sua definição também esteja investida de um gesto interpretativo, projetando um efeito de que 
se trata de um saber universal, indiferente à interpretação e às condições históricas. Desse modo, a gramática configura-se como um lugar onde a interpretação é negada, ela intervém o tempo todo, mas o sentido é dado como evidente, naturalizando-o no fio do discurso.

Considerando essas propriedades da definição, a gramática se assenta sobre o imaginário de completude do saber sobre a língua, imaginário esse que encontra na definição uma formulação privilegiada para a produção de efeitos de evidência. A definição é uma questão que permeia a gramática, por se tratar de uma formulação de aparência semanticamente inequívoca, que atribui a esse instrumento linguístico um efeito de precisão e interdito da dúvida. Nesse sentido, por meio de proposições de aparência semanticamente estável, a gramática constrói uma imagem que projeta um efeito de totalidade do saber sobre a língua, de forma que "a exigência de completude toma, então, uma coloração imaginária e se transpõe em termos de totalidade: totalidade qualitativa, isto é, perfeição [...]; totalidade quantitativa - é por isso que só concebemos uma gramática se ela for completa" (MILNER, 1987: 26).

Entretanto, trata-se de um efeito de totalidade e completude que projeta sobre a gramática uma imagem de obra acabada e de saber inquestionável e evidente. Partindo de tal perspectiva, não vemos a gramática como um objeto sacralizado com todas as respostas tidas como verdadeiras e universais, mas a vemos como resultado de um processo de construção de um saber que é constituído em condições históricas, determinadas por sujeitos afetados ideologicamente. Questionamos a gramática como espaço discursivo semanticamente estabilizado (PÊCHEUX, 2008 [1990]), construído por meio de proposições de aparência evidente, onde a interpretação é negada, isto é, o sujeito interpreta, mas nega que seu posicionamento parta de um gesto interpretativo. Desse modo, a gramática se constitui como o lugar da certeza e da verdade do saber sobre a língua, onde o sentido é vigiado para que não haja a possibilidade de poder vir a ser outro.

Agustini (2003) desenvolve um estudo, pautado em uma perspectiva enunciativa, acerca da textualização política do discurso da gramática, isto é, acerca dos modos de dizer que constituem os enunciados da gramática. A autora parte do pressuposto de que "a gramática apresenta formas textuais que detêm uma certa estabilidade, o que significa dizer que a sua escrita se estrutura em torno de "modos de dizer'" (p. 111). Desse modo, Agustini (Ibid.) privilegia alguns enunciados que contribuem para a constituição da gramática como um espaço discursivo semanticamente estabilizado, tais como as definições, os exemplos e as formulações de regras.

A autora considera que há dois processos estruturais das condições de produção da constituição do discurso da gramática, os quais contribuem para a eficácia (ideológica) de seu funcionamento. Segundo Agustini (Ibid.), "o primeiro refere-se ao jogo de imagens que se configura para o locutor e o destinatário do discurso da gramática e o segundo refere-se à construção do modo de dizer que torna (aparentemente) homogêneo e coerente o que, na sua constituição, está dividido" (p. 100).

Em relação ao jogo de imagens entre locutor e destinatário do discurso da gramática, a autora, a partir da noção de formações imaginárias (PÊCHEUX, 1969), sustenta que

a textualidade da gramática produz a imagem de que, subjaz à sua estrutura, perguntas e respostas, colocando o destinatário no lugar daquele que faz as perguntas, o que projeta no imaginário a imagem de que o gramático responde a essas questões, procurando satisfazer às expectativas do destinatário (aquele que pergunta por 'desejar' saber e conhecer a e sobre a língua) e, assim, colocá-lo na posição de aceitar 'sem ressalvas' o que é dito, segundo a imagem que lhe atribui e a imagem que produz de si (p. 102) 
Desse modo, trata-se de uma estratégia discursiva que tem como pressuposto a antecipação da imagem do destinatário, constituída a partir do lugar ocupado pelo locutor. Assim, tendo em vista a regulamentação dos modos de dizer na gramática, os quais determinam também a tomada de posição do sujeito ao constituir-se como gramático, o dizer do locutor inscreve-se em uma rede de dizeres que corresponde ao lugar social de gramático, cujo efeito de repetibilidade se dá pela permanência e pela configuração de tais modos de dizer na gramática. Segundo a autora, essa regulamentação dos modos de dizer produz um efeito de que o dizer do gramático está pautado na repetição e que as diferenças estariam restritas às explicações. Entretanto, segundo a autora, "o efeito de mesmo resulta tão-somente da conjunção que os modos de dizer que a gramática encerra tomam" (Ibid.: 108, grifo de autor). A partir do estudo depreendido, a autora sustenta que "os enunciados analisados depõem contra essa ilusão de que esses textos gramaticais seriam meras 'repetições' da mesma história” (p. 170).

De nossa parte, entendemos que o fato de haver modos de dizer próprios da formulação do gramático não limita o seu saber sobre a língua a uma mera repetição do que já está posto; trata-se, outrossim, de uma forma de tornar o dizer controlável e expor o sujeito à visibilidade. A regularidade de construção dos modos de dizer na gramática pode ser relacionada com a exigência de clareza, de desambiguização, de determinação, de perfeita legibilidade que, segundo Haroche (1992), são mecanismos de individualização, inscritos no postulado geral que subentende toda gramática. Segundo a autora, são processos de individualização do sujeito na gramática que encontram sua origem nas ideologias religiosas e jurídico-políticas e intervêm nas práticas de leitura e interpretação. Tais exigências de clareza e de desambiguização têm o objetivo de tornar o sujeito visível e controlável; além disso, simula dar a ele o controle sobre seu dizer, quando, na verdade, consiste numa manifestação de auto-repressão livremente consentida, induzida pelo Estado no indivíduo (Ibid.). Segundo a autora, esse lugar de visibilidade que o sujeito assume na gramática é também um lugar acessível a apenas alguns, negado à maioria, que é o próprio privilégio da interpretação, lugar esse que atribui visibilidade e autoria a um dado sujeito que sustenta um gesto interpretativo.

Além disso, esse efeito de completude do saber sobre a língua projeta também a imagem de uma língua ideal, perfeita e homogênea, que é aquela sustentada pelo gramático. Entretanto, a língua não pode ser apreendida na sua totalidade, porque ela é heterogênea por natureza. A gramática trabalha para que tais diferenças sejam apagadas e para que aquilo que não condiz com o que está sustentado na gramática seja considerado como erro ou desprovido de sentido. A gramática projeta uma imagem da língua, mas que não é a língua na sua totalidade, tampouco poderia estar no lugar de.

Concebemos a escrita e a gramática como invenções humanas, que, segundo Auroux (1992), constituem as duas maiores revoluções tecnológicas ${ }^{3}$ da história da humanidade. Para nós, trata-se de um saber construído para representar a linguagem e torná-la um objeto passível de estudo, na medida em que entendemos que "o processo de aparecimento da escrita é um processo de objetivação da linguagem, isto é, de representação metalingüística considerável e sem equivalente anterior" (AUROUX, 1992: 20). Auroux (Ibid.) considera

3 Na verdade, o autor considera três revoluções tecnológicas (ou tecnolinguísticas): a primeira foi a invenção da escrita, a segunda foi a gramatização das diferentes línguas do mundo (e não a invenção da gramática em si), e a terceira, a qual somos contemporâneos, é a mecanização das formas privilegiadas da comunicação (cf. AUROUX, 1998). 
ainda que o aparecimento da escrita pode ser considerado como a condição da possibilidade do saber linguístico, e a gramatização, por sua vez, "é um processo que conduz a descrever e a instrumentar uma língua na base de duas tecnologias, que são ainda hoje os pilares de nosso saber metalingüístico: a gramática e o dicionário" (Ibid., 65 [grifos do autor]). É importante destacar ainda que Auroux (Ibid.) considera o aparecimento da escrita e a gramatização como "processos", na medida em que questiona o aparecimento repentino de saberes sem relação com a história. Nesse sentido, na perspectiva do autor, mesmo quando se fala em "origem", "não se trata evidentemente de um acontecimento, mas de um processo que podemos delimitar num intervalo temporal aberto, às vezes consideravelmente longo" (Ibid.: 21).

Em relação à língua, não se poderia dizer que também consiste em uma invenção humana e, portanto, se não é uma invenção, também não poderia ser um instrumento. Benveniste (2005) leva até as últimas consequências a concepção de linguagem enquanto instrumento, questionando a exterioridade da linguagem em relação ao homem. Para esse autor, a linguagem não existe fora do homem, da mesma forma que só é possível colocar-se como sujeito na e pela linguagem, pois o "eu" não existe senão na linguagem.

É a partir de tais pressupostos que questionamos a pretensão da gramática, tanto de construir uma imagem de um objeto que lhe escapa, quanto de impor tal imagem como se fosse a língua na sua essência. Nesse sentido, a nossa proposta é investigar como se constitui esse imaginário de unidade da língua e como o gramático se significa enquanto sujeito ao designar a língua.

\section{Um gesto analítico: o gramático brasileiro e a gramática portuguesa}

A nossa proposta de análise tem o objetivo de investigar como se constitui o imaginário de unidade da língua na gramática a partir da forma como o sujeito a define e a designa. Ao desenvolvermos nosso estudo, partimos do pressuposto de que o trabalho do analista, segundo Orlandi (2005 [1999]), é, numa primeira etapa, desnaturalizar a relação palavra-coisa, desfazendo a ilusão de que aquilo que foi dito só poderia ser daquela maneira e não de outra. Essa desnaturalização é realizada por meio de dispositivos analíticos, relacionando o dito com o não dito e também àquilo que foi dito de outro modo em outro lugar, constituindo uma rede de famílias parafrásticas que remetem a dizeres que determinam o dizer do sujeito. Numa segunda etapa, segundo Orlandi (Ibid.: 78),

[...] o analista vai incidir uma análise que procura relacionar as formações discursivas distintas - que podem ter-se delineado no jogo de sentidos observado pela análise do processo de significação (paráfrase, sinonímia etc.) com a formação ideológica que rege essas relações.

Nesse sentido, partimos do pressuposto de que as palavras não são do sujeito, o que torna possível que as mesmas palavras possam significar diferente conforme a posição daqueles que as empregam, já que as palavras se deslocam no interdiscurso, o todo complexo dominante das formações discursivas (FDs). Considerando as diferentes formas de designar a língua, interessa-nos questionar como tais designações remetem a outros dizeres que constituem o processo discursivo em que a língua no/do Brasil é significada pelo colonizador.

A gramática que selecionamos como ponto de partida para a nossa reflexão é a Moderna Gramática Portuguesa (1977 [1961]), de Evanildo Bechara, gramática de grande circulação e de prestígio no âmbito do ensino no Brasil. Essa gramática foi publicada inicialmente por 


\section{Conexão Letras}

Eduardo Carlos Pereira e chamava-se Gramática Expositiva ${ }^{4}$ (1907). Essa obra desfrutava de ampla circulação no ensino gramatical e atingiu 102 edições. Entretanto, quando a Nomenclatura Gramatical Brasileira (NGB) entra em vigência, em 1959, aquelas gramáticas que já vinham sendo publicadas anteriormente passaram por reformulações, segundo as orientações da nova nomenclatura, para continuar circulando no âmbito do ensino. Desse modo, “com a morte de Eduardo Carlos Pereira, e as exigências estritas da NGB, sua adaptação é proposta por E. Bechara, o qual, ao apresentá-la, no entanto, é reconhecido não como possível adaptador do texto, mas como autor de outra gramática” (ORLANDI, 2002: 148).

Além disso, nessa época, as gramáticas brasileiras, além de terem uma terminologia gramatical própria, contam também com a caução do saber do linguista para legitimar a singularidade da língua no/do Brasil (Ibid.). Desse modo, consideraremos como a Moderna Gramática Portuguesa (1977 [1961]) se situa nessas condições históricas, buscando investigar como se constitui o imaginário de língua no discurso do gramático e como o sujeito se significa pela forma como ele designa a língua. Nessa gramática, selecionamos três recortes para a nossa análise. Tais recortes remetem à definição de língua sobre a qual repousa a gramática e também às formas como o gramático designa a língua. Eis os recortes selecionados para a nossa análise:

\begin{tabular}{|l|}
\hline \multicolumn{1}{|c|}{ Moderna Gramática Portuguesa (1977 [1961]) - Evanildo Bechara } \\
\hline R1 - \\
"Que é uma língua \\
Entende-se por língua ou idioma o sistema de símbolos vocais arbitrários com que um grupo \\
social se entende. Uma língua pode ser instrumento particular de um povo único, como acontece \\
com o chinês, o romeno, ou comum a mais de uma nação. Este é o caso do português, que serve \\
a Portugal, ao Brasil e colônias ultramarinas lusas. Este fato se explica historicamente pelos \\
capítulos de expansão e colonização dos povos. Falamos o português como língua oficial porque, \\
ao lado de outras instituições culturais, os portugueses no-la deixaram como traço de civilização \\
que aqui fundaram depois de 1500” (p. 23 [grifos do autor]) \\
\hline R2 - \\
"Uma língua de civilização apresenta as seguintes modalidades: \\
a) língua falada: instrumento de comunicação cotidiana, que, sem preocupação artística, tem a seu \\
dispor os múltiplos recursos lingüísticos da entonação e extralingüísticos da mímica, englobados \\
na 'situação' em que se acham falante e ouvinte; \\
b) língua escrita: instrumento de comunicação menos freqüente em que o escritor tem de suprir \\
os recursos que estão à disposição da língua falada. Foge, por isso, muitas vezes às expressões \\
comuns da linguagem ordinária para fins estéticos e expressivos. [...] O ponto culminante deste \\
afastamento é a língua literária, que é um aspecto da língua escrita, mas que com esta não se \\
confunde. É o instrumento de que se utilizam os escritores nas suas obras; exige um cultivo especial \\
e um ideal superior de expressão, além de estar sujeita aos preceitos das modas dominantes" (p. \\
23-24 [grifos do autor])
\end{tabular}

4 A Gramática Expositiva, de Eduardo Carlos Pereira, se filia a uma perspectiva pedagógica, na medida em que "a forma expositiva da gramática corresponde ao modo normativo que se estabelece como relação com a língua na escola" (ORLANDI, 2002, p. 145). Quando Evanildo Bechara retoma a Gramática Expositiva com vistas à "adaptá-la" à NGB, não se trata apenas de inserir os novos termos (im)postos pela nova nomenclatura. Trata-se de uma outra gramática que "se coloca em uma perspectiva em que aparece um movimento na direção de colocar junto o trabalho do gramático o do linguista" (Ibid., p. 148). Entretanto, no caso da edição da Moderna Gramática Portuguesa (1977 [1961]) que analisaremos no presente trabalho, o gramático se situa em uma posição mais conservadora e os saberes do linguista aparecem timidamente. 
R3 -

\section{"Língua geral e língua regional}

A língua espalhada por grande extensão de terra pode apresentar particularidades cujo conjunto caracteriza a língua regional, e os traços lingüísticos que aí ocorrem recebem o nome de regionalismos.

\section{Objeto da Gramática}

Mas dentro da diversidade das línguas ou falares regionais se sobrepõe um uso comum a toda área geográfica, fixada pela escola e utilizada pelas pessoas cultas: é isto que se constitui a língua geral, língua padrão ou oficial do país" (p. 24 [grifos do autor])

O primeiro recorte, que designamos como R1, remete à definição de língua proposta pelo gramático. Particularmente, nesse recorte, interessa-nos a definição de língua enquanto instrumento, tal como é concebida nos enunciados:

(1) "Uma língua pode ser instrumento particular..."

(2) “... que serve a Portugal, ao Brasil e colônias ultramarinas lusas”.

A língua definida enquanto instrumento tem uma função utilitária, como aponta a oração relativa "que serve a Portugal, ao Brasil e colônias ultramarinas lusas". Conceber a língua enquanto instrumento pressupõe a sua exterioridade em relação ao sujeito e também a possibilidade de o sujeito poder manipulá-la. Se a língua é exterior e é um instrumento, ela é uma invenção humana e o sujeito pode intervir sobre ela. Entretanto, a língua a que o gramático se refere em cujo controle acredita é uma língua imaginária, já que esta, na sua existência histórica, não pode ser apreendida na sua totalidade, nem pode ser fixada em parâmetros homogêneos. Esse imaginário de controle da língua permite ao gramático concluir que só há uma língua (a língua portuguesa) que se estende a diferentes povos, como Portugal, Brasil e "colônias ultramarinas lusas". Inclusive, essa designação "colônias ultramarinas lusas", que não inclui o Brasil e reforça que não se trata mais de uma colônia portuguesa, não menciona nem sequer o nome desses países a que se estende a língua portuguesa e coloca-os sob o domínio de Portugal, atribuindo um poder aos nossos antigos colonizadores.

Além disso, esse efeito de exterioridade da língua faz parecer que o brasileiro fala português porque quer, porque decidiu assim e escolheu o português como sua língua, apagando, desse modo, a história da relação dos brasileiros com a língua. Nesse apagamento, ressoa também o discurso do colonizador sobre o brasileiro, que retorna no discurso do gramático quando se trata de explicar porque o brasileiro fala português e não outra língua:

(3) "Falamos o português como língua oficial porque, ao lado de outras instituições culturais, os portugueses no-la deixaram como traço de civilização que aqui fundaram depois de 1500".

A imposição da língua portuguesa pelo colonizador é significada no discurso do gramático pelo eufemismo “... os portugueses no-la deixaram...”, fazendo ressoar como não dito o fato de que a língua portuguesa foi imposta por meio de um ato político aos povos indígenas que já tinham a sua língua, a qual foi suprimida pelo colonizador. Além disso, essa imposição do colonizador repousava sobre o imaginário de que ele era um povo superior e mais organizado e tal imaginário, portanto, dava-lhe o direito de submeter os povos indígenas à condição de colonizados e o de impor-lhes uma língua, uma religião, um poder. 


\section{Conexão Letras}

Esse já dito ressoa no enunciado “... como traço de civilização que aqui fundaram depois de 1500", fazendo significar que os povos indígenas não eram considerados civilizados e que isso só foi possível com a chegada dos portugueses no século XVI. O corte na história, “... fundaram depois de 1500”, nega a existência aos sujeitos e sua(s) língua(s) antes da chegada do europeu, legitimando o discurso do "descobrimento" do Brasil.

Em R2, destacamos a forma como a língua é designada por: "língua de civilização", "língua falada", "língua escrita", "língua literária". Trata-se de "modalidades" que uma "língua de civilização" pode se apresentar. Todas essas "modalidades" são definidas como "instrumentos":

(4) "língua falada: instrumento de comunicação cotidiana..."

(5) "língua escrita: instrumento de comunicação menos freqüente..."

(6) "língua literária [...] é o instrumento de que se utilizam os escritores nas suas obras..."

Essas designações "língua falada", "língua escrita", "língua literária”, que estão todas sob a designação "língua de civilização", não remetem a nenhuma forma de variedade linguística e tampouco à possibilidade de se ter outras línguas no Brasil que não seja a língua portuguesa. Essa forma de designar a língua faz significar o silenciamento de todas as outras línguas praticadas no Brasil e manifesta a força impositiva do discurso do Estado que, por sua vez, remonta ao discurso do colonizador, e que não cessa de retornar no discurso do colonizado. O "traço de civilização" a que o gramático refere é a própria língua do colonizador, porque esta possui uma escrita e também uma literatura. Segundo os critérios do gramático, portanto, as línguas que não tem escrita não poderiam consideradas "línguas de civilização", uma vez que a falta da escrita implica também a falta de "civilização".

Além disso, essas designações respondem a uma hierarquização que obedece a dois critérios: primeiro, o da frequência com que tais modalidades são usadas e o segundo, o da ascensão da escala a partir da relação do sujeito com a escrita. Quanto menos frequente, mais seleto é o público que a usa e mais culta é a modalidade, conforme a hierarquização do gramático:

(4) língua falada: instrumento de comunicação cotidiana, que, sem preocupação artística

(5) língua escrita: instrumento de comunicação menos freqüente em que o escritor tem de suprir os recursos que estão à disposição da língua falada. Foge, por isso, muitas vezes às expressões comuns da linguagem ordinária para fins estéticos e expressivos. [...]

(6) língua literária [...] exige um cultivo especial e um ideal superior de expressão, além de estar sujeita aos preceitos das modas dominantes” (p. 23-24 [grifos do autor])

Nessa escala, que tem seu ápice na escrita literária, atribui-se aos falantes níveis de hierarquização que variam conforme a sua relação com a escrita. Além disso, nessa escala, a língua falada é a que está mais distante de um ideal de superioridade e, nessa medida, atribui-se ao escritor a tarefa de "... suprir os recursos que estão à disposição da língua falada...", pressupondo que a língua falada é incompleta e problemática. Entretanto, podese alcançar "um ideal superior de expressão" somente através da escrita literária, porque é nesse estágio em que o ideal da língua se manifesta e esse é o parâmetro sobre o qual a gramática se apoia para formulação de regras e normas. 
Essas designações repousam sobre o imaginário de homogeneidade da língua e convergem para a constituição de uma língua imaginária cada vez mais distanciada da realidade da língua, tal como ela se constitui na sociedade, na história e na relação com os falantes.

No terceiro recorte, R3, destacamos outras designações: "língua regional" e "língua geral", onde "língua geral" está numa relação sinonímica com "língua padrão" e "língua oficial". A definição de "língua regional" como "língua espalhada por grande extensão de terra..." associa a noção de língua em relação à terra enquanto espaço geográfico. Nessa definição, mais uma vez, omite-se a relação do sujeito com a língua, esse sujeito que fala a língua fora dos parâmetros da gramática não existe aos olhos do gramático. Além disso, a designação "língua regional" é introduzida primeiramente para, logo em seguida, ser colocada em oposição à "língua geral”, que, segundo o gramático, sobrepõe-se à "língua regional", constituindo, desse modo uma hierarquização em relação ao modo como a língua é distribuída no espaço geográfico. Essa hierarquização ressoa no discurso do gramático pelo modo como a "língua regional" é sufocada pela "língua geral", como aponta o enunciado “... dentro da diversidade das línguas ou falares regionais se sobrepõe um uso comum a toda área geográfica...”. Essa sobreposição da "língua geral" é justificada pelo fato de ser uma modalidade “... fixada pela escola e utilizada pelas pessoas cultas...”. Nesse sentido, o gramático hierarquiza a língua, conforme o grau de escolarização dos falantes, e coloca a "língua geral" em um patamar que somente tem acesso aqueles que têm um maior grau de escolarização e de cultura. Dessa forma, manifesta-se a força impositiva e excludente da gramática, que elege como padrão a modalidade dos mais escolarizados para excluir socialmente os menos aparelhados linguisticamente. A sobreposição da "língua geral" em relação à "língua regional" aponta para o forte controle da escola e da gramática para impor um imaginário de língua homogênea sobre as formas não padronizadas e, assim, legitimar o discurso de que o brasileiro não sabe falar a própria língua.

Além disso, é preciso destacar que a designação "língua geral" faz ressoar um outro discurso que remonta ao período de colonização quando a designação "língua geral" remetia à língua tupi, a língua dos indígenas, colonizados pelo europeu. No discurso do gramático, "língua geral" não é a língua do colonizado, mas a língua que foi imposta pelo colonizador e que hoje é a "língua padrão" e a "língua oficial" do Estado. Essa designação retorna como se mostrasse ao europeu que o brasileiro, enfim, aprendeu a repetir que a "língua geral" só poderia ser a língua portuguesa, a língua do colonizador, construindo uma memória (artificial) sobre a história de colonização e de submissão de um povo sobre outro. É nessa medida que "por aí vemos que a ideologia não 'aparece' do nada em um passe de mágica. Ela tem uma materialidade e o discurso é o lugar em que temos acesso a essa materialidade" (ORLANDI, 1990: 47). O efeito ideológico de assujeitamento se manifesta no discurso do brasileiro que faz ressoar o discurso do colonizador, na medida em que se naturaliza uma história de imposição de uma língua em detrimento de todas as demais, fazendo significar a relação do sujeito com a língua tal como foi significada no discurso do colonizador.

\section{CONSIDERAÇÕES FINAIS:}

Através do estudo depreendido, buscamos compreender como se constitui o imaginário de unidade da língua na gramática a partir da forma como o sujeito a define e a designa. Selecionamos, para isso, uma gramática brasileira, designada "Moderna Gramática Portuguesa", de Evanildo Bechara, publicada em um período em que a produção 


\section{Conexão Letras}

de instrumentos linguísticos no Brasil destaca-se, sobretudo, por sustentar-se sobre bases autônomas e legitimar as diferenças entre o português do/no Brasil e o português europeu.

Escolhemos, como recorte de análise, a definição de língua e as diferentes formas como o gramático a designa. O gramático defende uma concepção de língua enquanto instrumento, que pressupõe a separação entre o sujeito e a língua, permitindo, desse modo, que o sujeito possa intervir sobre ela. Essa concepção sustenta um imaginário de língua homogênea e única, tanto no Brasil como em relação a Portugal. As designações "língua falada", "língua escrita", "língua literária" não apontam para a heterogeneidade, mas para uma estratificação da língua, conforme a relação do sujeito com a escrita. Em uma escala ascendente, quanto maior o domínio da escrita, mais se avança em relação a uma língua ideal, praticada por um grupo cada vez mais seleto. As designações "língua regional" e "língua geral" estabelecem entre si uma relação de sobreposição, na medida em que o gramático só admite a possibilidade uma "língua regional" com a condição de a "língua geral" sobrepor-se à primeira. Além disso, o gramático coloca a "língua geral", considerada por ele como a língua padrão, a língua oficial, num patamar inatingível para aqueles que não dominam a escrita, uma vez que esta é "fixada pela escola e utilizada pelas pessoas cultas". Nega-se ao falante o direito à própria língua e exclui-se socialmente aqueles que não dominam a escrita e a norma imposta pela gramática.

É nessa medida que entendemos a força impositiva e o poder de exclusão da gramática, de modo que sustenta uma língua ideal, que não se verifica na prática corrente, e classifica essa mesma língua em níveis diferenciados, conforme a relação do sujeito com a escrita. Impõe-se uma série de etapas e de conhecimentos, cada vez mais inalcançáveis ao sujeito para melhor submetê-lo e poder excluí-lo socialmente por não dominar a sua própria língua. Trata-se de uma submissão livremente consentida (HAROCHE, 1992), que constitui o imaginário de unidade e homogeneidade da língua portuguesa, sustentado na/ pela gramática, a qual faz ressoar o discurso do colonizador e a forma como o brasileiro foi significado em relação a sua própria língua.

\section{REFERÊNCIAS}

ANCHIETA, José. [1595] Artes de gramática da língua mais falada na Costa do Brasil. Edição fac-similar. São Paulo: Edições Loyola, 1990.

AUROUX, Sylvain. A revolução tecnológica da gramatização. Campinas, SP: Editora da Unicamp, 1992.

. A filosofia da linguagem. Traduzido por José Horta Nunes. Campinas, SP: Editora da Unicamp, 1998.

AGUSTINI, Cármen Lúcia Hernandes. A enunciação do transbordamento das regras : a estilística no discurso da gramática. 2003. 204 f. Tese (Doutorado em Linguística) Universidade Estadual de Campinas, Campinas/SP, 2003.

BECHARA, Evanildo. [1961]. Moderna Gramática Portuguesa: curso de $1^{\circ}$ e $2^{\circ}$ graus. $22^{\mathrm{a}}$ ed. São Paulo: Editora Nacional, 1977.

BENVENISTE, Émile. Problemas de Lingüística Geral I. Traduzido por Maria de Glória e Maria Luisa Néri. 5. ed. Campinas, SP: Pontes, 2005.

DIAS, Luiz Francisco. Os sentidos do idioma nacional: as bases enunciativas do nacionalismo lingüístico no Brasil. Campinas, SP: Pontes, 1996.

GUIMARÃES, Eduardo. Língua de Civilização e Línguas de Cultura: A Língua Nacional do Brasil. In: BARROS, Diana (Org.). Os Discursos do descobrimento: 500 e mais anos de discurso. São Paulo: Editora da Universidade de São Paulo; FAPESP, 2000. 

2003: 47-53.

Enunciação e política de línguas no Brasil. Revista Letras, Santa Maria, no 27 ,

HAROCHE, Claudine. Fazer dizer, querer dizer. Traduzido por Eni Orlandi com a colaboração de Freda Indursky e Marise Manoel. São Paulo: Hucitec, 1992.

MARIANI, Bethania. Políticas de Colonização Linguística. Revista Letras, Santa Maria, $\mathrm{n}^{\circ}$ 27, 2003: 73-82.

MILNER, Jean-Claude. O amor da língua. Traduzido por Ângela Cristina Jesuino. Porto Alegre, RS: Artes Médicas: 1987.

ORLANDI, Eni. Terra à vista!: discurso do confronto: velho e novo mundo. São Paulo: Cortez; Campinas, SP: Editora da Universidade de Campinas, 1990.

. Lingua e conhecimento linguístico: para uma história das idéias no Brasil. São

Paulo: Cortez, 2002: 65-73.

. Análise de Discurso: princípios e procedimentos. 6. ed. Campinas, SP: Pontes, 2005.

PÊCHEUX, Michel. [1990] Discurso: estrutura ou acontecimento. Traduzido por Eni Orlandi. 5. ed. Campinas, SP: Pontes, 2008.

. [1988] Semântica e discurso: uma crítica à afirmação do óbvio. Traduzido por E.

Orlandi. 4. ed. Campinas, SP: Editora da Unicamp, 2009.

. [1969] Por uma análise automática do discurso: uma introdução à obra de Michel

Pêcheux. GADET, Françoise; HAK, Tony (Orgs.). Traduzido por Bethania Mariani [et. al.]. 3. ed. Campinas, SP: Editora da Unicamp, 1997.

SCHERER, Amanda Eloina. A procura da língua universal: entre a memória e história. In: ZANDWAIS, Ana. (Org.) História das ideias: diálogo entre linguagem, cultura e história. Passo Fundo: Universidade de Passo Fundo, 2012. p. 157-174.

ZANDWAIS, Ana. Subjetividade, sentido e linguagem: desconstruindo o mito da homogeneidade da língua. In: . História das ideias: diálogo entre linguagem, cultura e história. Passo Fundo: Universidade de Passo Fundo, 2012. p. 175-191. 